
Cellular Physiology Cell Physiol Biochem 2018;48:1123-1138 and Biochemistry Published online: July 24,2018
(C) 2018 The Author(s)
Published by S. Karger AG, Basel
www.karger.com/cpb

\title{
Targeting of the C-Jun/BCL-XL/P21 Axis Accelerates the Switch from Senescence to Apoptosis Upon ROC1 Knockdown in Gastric Cancer Cells
}

Ping Chen ${ }^{a, b}$ Xiaoting Luo ${ }^{a}$ Zhihui Che ${ }^{a}$ Wenli Zhang ${ }^{a}$ Fuchen Liu ${ }^{a, c}$ Daisen Hou ${ }^{b}$ Dongqin Yang ${ }^{a}$ Jie Liu ${ }^{a, b}$

aDepartment of Digestive Diseases of Huashan Hospital, Fudan University, Shanghai, ' ${ }^{\text {Institute of }}$ Biomedical Science of Shanghai Medical School, Fudan University, Shanghai, 'The Third Department of Hepatic Surgery, Eastern Hepatobiliary Surgery Hospital, Second Military Medical University, Shanghai, China

\section{Retraction Statement see Next Page}




\section{Retraction Statement}

Chen P, Luo X, Che Z, Zhang W, Liu F, Hou D, Yang $D$, Liu J, entitled "Targeting of the C-Jun/BCLXL/P21 Axis Accelerates the Switch from Senescence to Apoptosis Upon ROC1 Knockdown in Gastric Cancer Cells" [Cell Physiol Biochem 2018;48:11231138, DOI: 10.1159/000491979].

We are very sorry for that in recent studies we obtained some new data which is inconsistent with part of the results in this article, we need further confirmatory tests to verify these results. To avoid any negative impact on other's research in this field, after serious consideration, all of the authors have decided to withdraw it from publication.

We sincerely apologize for our decision and appreciate the efforts of the editors, reviewers and publishers.

Ping Chen (First author) 